\title{
O PLANO DIRETOR DE RIBEIRÃO DAS NEVES - MG: ANÁLISE DE UMA CIDADE FORA DO PLANO.
}

\author{
Osmar Henrique Ribeiro da Silva ${ }^{1}$
}

\author{
Ítalo Itamar Caixeiro Stephan ${ }^{2}$
}

\begin{abstract}
Resumo
O Plano Diretor do município de Ribeirão das Neves, município localizado na Região Metropolitana de Belo Horizonte está inserido no contexto nacional de obrigatoriedade de elaboração de planos para a organização municipal. Nesse sentido este trabalho tem como objetivo analisar o Plano Diretor do município, desde sua aprovação, conteúdo à aplicação de suas diretrizes. Para tanto foram feitos levantamentos bibliográficos sobre o crescimento e desenvolvimento da cidade, assim como a pesquisa em documentos que pudessem comprovar a ação, ou não, do Plano Diretor. Através dessa metodologia foi observado que a Lei Complementar 036/2006, que instituiu o Plano Diretor em Ribeirão das Neves, possui um conteúdo reduzido ao discurso de diretrizes não aplicáveis e abertas a inúmeras interpretações. Em um histórico baseado na implantação de penitenciárias, o Plano Diretor não possui qualquer referência às sete unidades prisionais presentes no território do município. Aliado a esse cenário a cidade ainda enfrenta problemas de pobreza e altos índices de violência urbana, um espaço a margem das políticas e projetos que visam melhorar o contexto metropolitano. Conclui-se que a necessidade de organização e integração do espaço fragmentado de Ribeirão das Neves juntamente com o estigma de "cidade-presídio" e "cidade-dormitório" coloca a cidade fora do plano, seja ele o Plano Diretor ou dos planos de projetos metropolitanos.
\end{abstract}

Palavras-chave: Ribeirão das Neves; Região Metropolitana de Belo Horizonte; Plano Diretor; Segregação Socioespacial.

\section{THE PLAN RIBEIRÃO DIRECTOR OF NEVES - MG: ANAL YSIS OF A PLAN OUT OF TOWN.}

\section{Abstract}

\footnotetext{
Geógrafo e Mestrando em Arquitetura e Urbanismo, Universidade Federal de Viçosa. osmarhrs@gmail.com.

${ }^{2}$ Arquiteto e Doutor em Arquitetura e Urbanismo, Professor Associado I da Universidade Federal de Viçosa.stephan@ufv.br.
} 


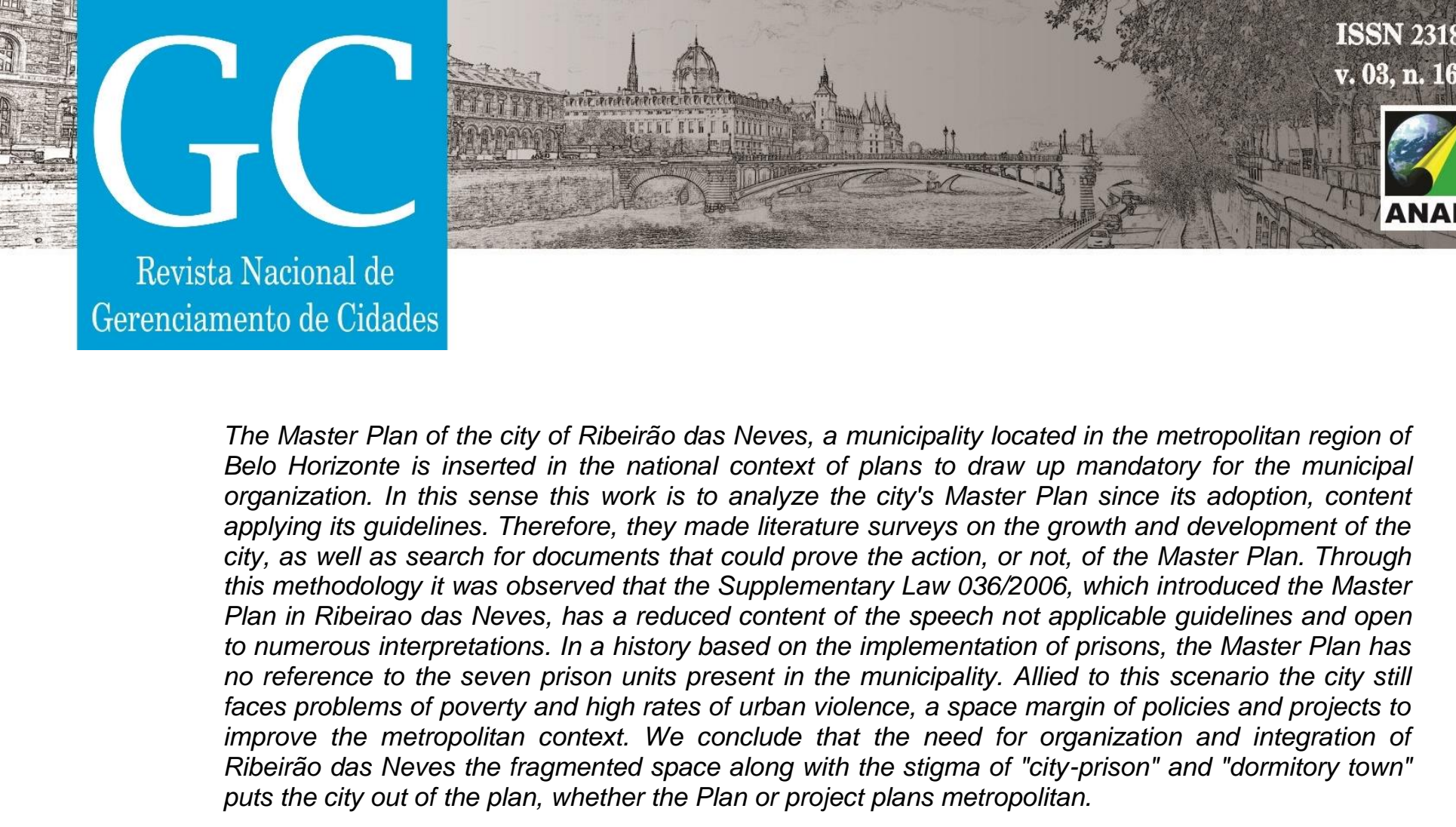

The Master Plan of the city of Ribeirão das Neves, a municipality located in the metropolitan region of Belo Horizonte is inserted in the national context of plans to draw up mandatory for the municipal organization. In this sense this work is to analyze the city's Master Plan since its adoption, content applying its guidelines. Therefore, they made literature surveys on the growth and development of the Plan in Ribeirao das Neves, has a reduced content of the speech not applicable guidelines and open to numerous interpretations. In a history based on the implementation of prisons, the Master Plan has no reference to the seven prison units present in the municipality. Allied to this scenario the city still

Keywords: Ribeirao das Neves; Metropolitan Region of Belo Horizonte; Master Plan; Socio-Spatial Segregation.

\title{
EL DIRECTOR DEL PLAN DE RIBEIRÃO NEVES - MG: ANÁLISIS DE UN PLAN DE FUERA DE LA CIUDAD.
}

\begin{abstract}
Resumen
El Plan Director de la ciudad de Ribeirão das Neves, un municipio situado en la región metropolitana de Belo Horizonte se inserta en el contexto nacional de los planes para elaborar obligatorio para la organización municipal. En este sentido, este trabajo es analizar el Plan Maestro de la ciudad desde su aprobación, el contenido de la aplicación de sus directrices. Por lo tanto, hicieron encuestas literatura sobre el crecimiento y desarrollo de la ciudad, así como la búsqueda de documentos que podrían resultar de la acción, o no, del Plan Maestro. A través de esta metodología se observó que la Ley Complementaria 036/2006, que introdujo el Plan Maestro en Ribeirao das Neves, tiene un contenido reducido del discurso directrices no aplicables y abierta a numerosas interpretaciones. En una historia basada en la aplicación de las prisiones, el Plan Maestro no hace referencia a las siete unidades penitenciarias presentes en el municipio. Aliado a este escenario la ciudad todavía se enfrenta a problemas de la pobreza y los altos índices de violencia urbana, un margen de espacio de políticas y proyectos para mejorar el contexto metropolitano. Llegamos a la conclusión de que la necesidad de la organización e integración de Ribeirão das Neves el espacio fragmentado, junto con el estigma de la "ciudad-prisión" y "ciudad dormitorio" pone la ciudad fuera del plan, si los planes de plan o proyecto metropolitana.
\end{abstract}

Palabras clave: Ribeirão das Neves; Región metropolitana de Belo Horizonte; Plan Maestro; La segregación socio-espacial.

\section{INTRODUÇÃO}

A preocupação com o ordenamento do espaço não é um tema novo, ao observamos a história das cidades veremos que registros antigos mostram que algumas aglomerações de pessoas já possuíam um ordenamento nas suas 


\section{Revista Nacional de}

ocupações territoriais. Com o desenvolvimento e crescimento das cidades resultou em um aumento do número de pessoas vivendo em áreas urbanas, de modo que o planejamento surge como resposta para os problemas socioespacias que a cidades passam a enfrentar.

A expressão planejamento urbano passa então a fazer parte do discurso político devido à necessidade contornar os problemas existentes e produzir planos para ordenar a expansão da cidade. Segundo Villaça (1999) o nascimento do planejamento urbano no Brasil se dá em 1875, quando a então Comissão de Melhoramentos da Cidade do Rio de Janeiro, criada em 1874 pelo Ministro do Império João Alfredo Correa de Oliveira, apresenta seu primeiro relatório, no qual são utilizados pela primeira vez dois conceitos-chave: o de plano e o de conjunto geral ou global, associados ao espaço urbano (VILLAÇA, 1999: 194-195).

Nas últimas décadas o planejamento urbano que se desenvolveu no Brasil se manifestou através de algumas modalidades, sendo uma das mais difundidas através do plano diretor. Uma forma de planejamento urbano que se firmou no âmbito das reivindicações populares no espaço urbano. Segundo Villaça o plano diretor:

Seria um plano que, a partir de um diagnóstico científico da realidade física, social, econômica, política e administrativa da cidade, do município e de sua região, apresentaria um conjunto de propostas para o futuro desenvolvimento socioeconômico e futura organização espacial dos usos do solo urbano, das redes de infraestrutura e de elementos fundamentais da estrutura urbana, para a cidade e para o município, propostas estas definidas para curto, médio e longos prazos, e aprovadas por lei municipal. (VILLAÇA, 2012, p. 186).

Para a Associação Brasileira de Normas Técnicas o Plano Diretor seria a ferramenta fundamental para o planejamento municipal, de modo a implantar a política de desenvolvimento urbano que conduz a gestão pública (ABNT, 1991). E uma última definição é utilizada no Estatuto da Cidade (Lei 10.257 de 10 de Julho de 2001), que conceitua o Plano Diretor como "o instrumento básico da política de desenvolvimento e expansão urbana". 



\section{Revista Nacional de}

Gerenciamento de Cidades

(Cedeplar) - os três últimos localizados em Belo Horizonte - e as Bibliotecas da UFV e UFMG.

\section{RIBEIRÃO DAS NEVES: SEGREGAÇÃO SOCIOESPACIAL NA RMBH}

O município de Ribeirão das Neves, localizado no Vetor Norte da Região Metropolitana de Belo Horizonte, é um dos núcleos mais antigos da região, seu povoado tem início por volta de 1747. Ao longo dos anos a cidade cresceu tendo base as fazendas demarcadas ao redor da igreja, mas foi só a partir do início da construção da Penitenciária Agrícola de Neves (PAN) que o núcleo urbano começa a se desenvolver. A migração para os arredores do presídio era composta de familiares dos servidores e dos detentos (SOUZA et. al, 2011). A emancipação do povoado aconteceu em 1953 passando então a receber o nome de Ribeirão das Neves e sendo composta de dois distritos, a Sede e Justinópolis.

Pode-se dizer que foi após a implantação da Penitenciária Agrícola de Neves em 1938, Neves passa a ser reconhecida, tendo uma função diante da região metropolitana:

\footnotetext{
Pode-se afirmar que a Penitenciária foi construída para ser modelo não só para o Brasil, mas a América Latina. Passou a ser conhecida universalmente e a ser citada na França e na Itália. Ela representava, de fato, um marco para a reforma do sistema penitenciário, 'era um estabelecimento de reeducação, constituído segundo os moldes mais eficientes adaptados ao nosso meio essencialmente rural. (SOUSA, 2002, p. 64).
}

Portanto, a PAN teve papel fundamental na estruturação espacial da cidade, pois, além de concentrar população ao seu redor, ela significou um referencial forte da paisagem para a população. Com a instalação de outras novas unidades penitenciárias, de acordo com Campos (2009) Neves passa a inserir o espaço metropolitano com a designação de "cidade-presídio"; fato que desestimulou o seu crescimento econômico e a valorização do espaço do distrito Sede. Já o Distrito de Justinópolis, inseriu-se no espaço metropolitano ao passo em que se conurba com 
Revista Nacional de

Gerenciamento de Cidades

Belo Horizonte, por Venda Nova, e ligando-se a Neves apenas pelo vínculo administrativo.

A intenção do governo do Estado era transformar o município em um "espaço carcerário", uma "cidade-presídio", devido às características do território nevense: a proximidade com a capital, ausência de atrativos para desenvolvimento econômico da cidade, etc. A falta de atenção para com a ordenação municipal repete-se, desde a construção da PAN, até os dias atuais. Como podemos perceber as construções das unidades prisionais não foram acompanhadas de investimentos significativos nos setores básicos do município como educação, saúde, infraestrutura, geração de empregos, saneamento e habitação. Esse contexto proporcionou a Neves ser o vetor de crescimento de loteamentos precários que visavam uma população de baixa renda.

O município de Ribeirão das Neves registrou na década de 1970 um crescimento urbano da ordem de $27 \%$ a.a., a mais alta taxa registrada na $\mathrm{RMBH}$ (IBGE, Censo 1970 - 2000). Esta dinâmica demográfica pode ser explicada, em parte, pelo processo de conurbação com Belo Horizonte, pelo funcionamento do mercado imobiliário e o baixo custo de seus terrenos. Aliados a uma omissão do poder público em implantar infraestruturas básicas para população e atrativos econômicos que contribuíssem para o desenvolvimento da cidade, tal crescimento levou à intensa ocupação de seu território por uma população de baixa renda, determinando o estigma de cidade dormitório.

De acordo com o Plano de Desenvolvimento Integrado de Ribeirão das Neves (1980, p. 17) a localização da população no município em questão era dividida de acordo com tal ordenação: a Sede Municipal encontrava-se ocupada por áreas em torno do centro, estendendo-se ao longo das estradas de ligação com Pedro Leopoldo e Venda Nova e, ainda, paralelamente ao Ribeirão das Neves e Córrego do Café que constituíam, junto com a área da Penitenciária, condicionantes da ocupação da região. $\mathrm{Na}$ área do distrito de Justinópolis, a ocupação se dava nos dois pequenos núcleos de Justinópolis e Areias e, de maneira rarefeita, ao longo das 


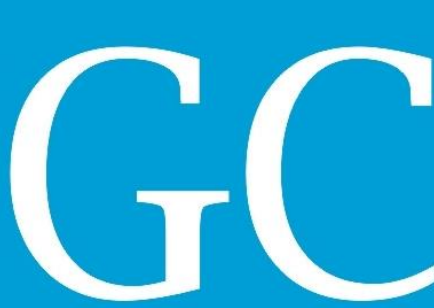

Revista Nacional de

Gerenciamento de Cidades

estradas de ligação de Justinópolis com a Sede e com Areias. O restante do município era ocupado por sítios e fazendas, devido ao grande potencial agrícola da região ${ }^{4}$. A população rural do município se localizava, principalmente, no distrito de Justinópolis.

Tabela 1: Ribeirão das Neves - Avaliação do Parcelamento da terra (1970 - 2005)

\begin{tabular}{lllllll}
\hline & $\begin{array}{l}\text { Sede } \\
\text { Área Loteada }\end{array}$ & No Lotes & $\begin{array}{l}\text { Justinópolis } \\
\text { Área } \\
\text { Loteada* }\end{array}$ & $\begin{array}{l}\text { Ro } \\
\text { Lotes }\end{array}$ & $\begin{array}{l}\text { Ribeirão das Neves } \\
\text { Loteada* }\end{array}$ & $\begin{array}{l}\text { № } \\
\text { Lotes }\end{array}$ \\
\hline $\mathbf{1 9 7 0}-\mathbf{1 9 7 4}$ & 4.116 .460 & 2.486 & 2.150 .232 & 4.114 & 6.266 .692 & 6.600 \\
$\mathbf{1 9 7 5}-\mathbf{1 9 7 9}$ & 11.976 .092 & 18.875 & 6.474 .976 & 10.076 & 18.451 .068 & 28.951 \\
$\mathbf{1 9 8 0}-\mathbf{1 9 8 9}$ & 5.747 .226 & 7.297 & & & 5.747 .226 & 7.297 \\
$\mathbf{1 9 9 0}-\mathbf{1 9 9 9}$ & 7.960 .724 & 14.260 & 2.738 .164 & 4.607 & 10.698 .888 & 18.867 \\
$\mathbf{2 0 0 0}-\mathbf{2 0 0 5}$ & 1.028 .199 & 2.907 & 382.268 & 1.327 & 1.410 .467 & 4.234 \\
\hline Total & $\mathbf{3 0 . 8 2 8 . 7 0 1}$ & $\mathbf{4 5 . 8 2 5}$ & $\mathbf{1 1 . 7 4 5 . 6 4 0}$ & $\mathbf{2 0 . 1 2 4}$ & $\mathbf{4 2 . 5 7 4 . 3 4 1}$ & $\mathbf{6 5 . 9 4 9}$ \\
\hline${ }^{*} \mathbf{m}^{2}$. & & & & & & \\
\hline
\end{tabular}

Fonte: PLAMBEL (1983). Modificado pelo autor.

Segundo Souza (2008) Ribeirão das Neves caracteriza-se por ser um o município que possui uma 'incapacidade financeira' de disponibilizar incentivos para o crescimento da indústria ao mesmo tempo em que a ausência de mão de obra qualificada e o estigma de cidade presídio não favoreceram a instalação de indústrias e de companhias no território nevense. Aliada a isso, as características do solo local que não permitiam uma produtividade relevante, a tendência de desvalorização do preço da terra e também a supressão de leis e regulamentos. No que diz respeito à qualidade dos loteamentos, os proprietários das terras de Neves viam na implantação de novos loteamentos uma forma rentável de utilização do território pouco valorizado pela indústria, mas interessante para a população de baixa renda que não possuía condições de pagar para viver na capital.

De acordo com os estudos do PLAMBEL (1983), o processo de loteamento das terras do município de Neves foi fortemente influenciado pela expansão urbana de Belo Horizonte em direção à região norte da capital, induzido pela construção do

\footnotetext{
${ }^{4}$ A expansão populacional do município, concomitantemente ao processo de parcelamento do solo rural para usos urbanos reduziu as atividades agrícolas, num processo que se acentuou a partir de 1975. (Plano de Desenvolvimento Integrado de Ribeirão das Neves, 1990).
} 
Revista Nacional de

Gerenciamento de Cidades

complexo de lazer da Pampulha e da abertura da Avenida Antônio Carlos. Mas é importante ressaltar que, naquele período, o grau de ocupação dos mesmos era extremamente baixo, o que se torna facilmente perceptível ao se verificar o ritmo de crescimento populacional do município nos anos 50.

O estudo realizado pelo PLAMBEL, Mercado da Terra na RMBH (1987) aponta algumas características do crescimento e ocupação do espaço de Ribeirão das Neves. Segundo tal estudo a "ocupação extensiva e descontínua; supervalorização das áreas ocupadas; degradação de áreas densamente ocupadas; e estratificação e segregação do espaço" foram favorecidas por uma lógica de funcionamento do mercado de terras, em que a variação de preço da terra é determinante da estrutura urbana.

De acordo com Souza (2002, p. 81) foi no ano de 1969 que o mercado imobiliário volta sua atuação exatamente para os municípios que apresentaram condições mais permissivas para promover loteamentos para a população de baixa renda, uma vez que, nesta época, as exigências estabelecidas pelo Município de Ribeirão das Neves, ao final dos anos de 1970, eram menos rigorosas do que as exigências estabelecidas pelo conjunto metropolitano, o que proporcionava vantagens aos loteadores para implementarem seus projetos no município. Dos cento e dez loteamentos identificados, apenas 4,7\% não foram aprovados pelas autoridades locais. No entanto, somente $7,4 \%$ foram aprovados pelo PLAMBEL, desconsiderando-se os quarenta e dois que foram aprovados pelo município antes que a aprovação pelo PLAMBEL passasse a ser uma exigência metropolitana. É importante ressaltar que, a grande maioria dos projetos foi implementada no território de Ribeirão das Neves, mesmo não tendo correspondido aos critérios regulamentados pelo PLAMBEL, fato que demonstra os altos níveis de permissividade e precariedade contida nessa produção.

Segundo funcionária da administração pública de Ribeirão das Neves as grandes construtoras, como a Probase, Tenda, Ascop e Passos anunciavam seus empreendimentos: lotes a preços acessíveis para uma população que buscava o 
Revista Nacional de

Gerenciamento de Cidades

'sonho da casa própria' em uma região próxima a capital. O pagamento dos lotes era feito com uma entrada por volta de 1.000 reais e o restante em inúmeras parcelas que eram reajustadas de acordo com o salário dos clientes. Após a venda da grande maioria dos lotes as empresas não terminavam os serviços de implantação de infraestruturas como iluminação das vias, calçamento das ruas, instalação de drenagem pluvial e etc., cabendo à prefeitura o ônus da instalação desses serviços.

Mesmo com essa situação, em 1971, a Prefeitura de Ribeirão das Neves aprovou na Sede do município, a instalação do Bairro Santa Marta, com 677 lotes de 360 metros quadrados. Havia nele uma carência quase que absoluta, contando apenas com o atendimento parcial das redes de iluminação pública e energia elétrica. As vias de acesso eram de terra, e não contava com serviços de transporte coletivo, água, esgoto e nem de coleta da água pluvial. Esse era o segundo maior loteamento aberto no município nos últimos 20 anos. O primeiro havia sido implantado em 1953, em Justinópolis - o Bairro Botafogo. Dividido em duas seções, o loteamento apresenta 1710 lotes e era servido apenas por transporte coletivo, energia elétrica e, parcialmente, pela rede de iluminação pública.

Conforme o documento, Mercado da Terra na RMBH, os municípios de Ibirité e Ribeirão das Neves, onde não havia restrições para aprovação de loteamentos, concentravam $53,8 \%$ dos lotes aprovados no aglomerado metropolitano. Eram lotes destinados principalmente às populações de nível econômico mais baixo. Nesse contexto, o mercado imobiliário encontrou em Ribeirão das Neves o local ideal para atuar naquela linha, dando continuidade ao processo clandestino de ocupação da região de Venda Nova (PLAMBEL, 1987, p.144).

$\mathrm{Na}$ Tabela 2 observamos que o município de Ribeirão das Neves recebe, a partir de 1972, um número de loteamentos que crescem em quantidade até 1976. Segundo Souza (2002, p. 82), a década de 70 nesta cidade tem um significado especial, uma vez que no contexto metropolitano e, principalmente, em Ribeirão das Neves há um crescimento populacional recorde. 


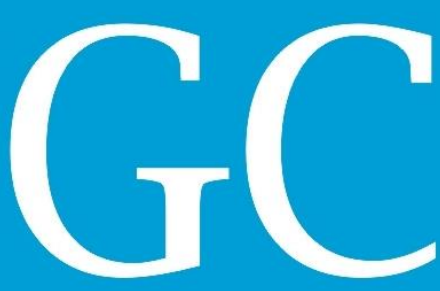

Revista Nacional de

Gerenciamento de Cidades

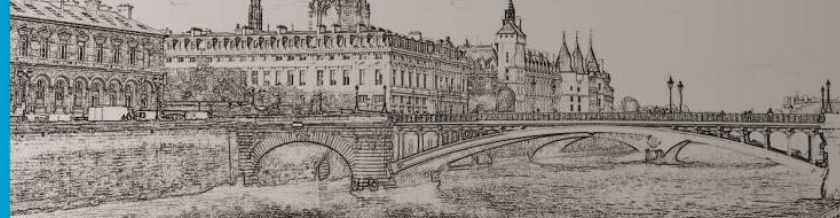

\begin{tabular}{|c|c|c|c|c|c|c|}
\hline Município & 1972 & 1973 & 1974 & 1975 & 1976 & Total \\
\hline $\mathrm{BH}$ & & 2 & 7 & 2 & 12 & 23 \\
\hline Betim & & & & 2 & 8 & 10 \\
\hline Contagem & & 1 & 1 & 1 & & 3 \\
\hline Lagoa Santa & & & & 1 & 1 & 2 \\
\hline Nova Lima & 1 & & & 3 & 5 & 9 \\
\hline Pedro Leopoldo & & & 1 & & & 1 \\
\hline Ribeirão das Neves & 3 & 7 & 3 & 5 & 17 & 35 \\
\hline Rio Acima & & & & 1 & 4 & 5 \\
\hline Santa Luzia & & & 1 & 1 & 5 & 7 \\
\hline Vespasiano & & & & & 1 & 1 \\
\hline Total & 4 & 10 & 13 & 16 & 53 & 96 \\
\hline
\end{tabular}

Fonte: Pesquisa Mercado da Terra - PLAMBEL, 1987.

É importante destacar neste período que todo o aglomerado metropolitano teve seu espaço urbano expandido. Como podemos observar, entretanto, o maior número de lançamentos ocorreu em Belo Horizonte e Ribeirão das Neves, onde se concentram 60\% dos loteamentos novos (PLAMBEL, 1987, p.146).

Como dito anteriormente a grande maioria dos lotes em Neves eram destinados às classes menos favorecidas devido aos preços menos onerosos, sendo assim os loteamentos que surgiram ao longo da década de 1970 em Ribeirão das Neves representaram para muitos uma oportunidade, senão a única, de adquirir moradia própria. Representaram, também, para as pessoas que foram morar nestas áreas, a chance de continuar residindo nas proximidades da capital e, portanto, de estar inserido em seu mercado de trabalho. (SOUSA, 2002, p. 156).

As fotos abaixo ilustram a realidade de alguns loteamentos no município de Ribeirão das Neves. $O$ processo de implantação precária dos loteamentos nas décadas passadas, 70 e 80 , reflete na condição atual dos bairros procedentes desses empreendimentos. 

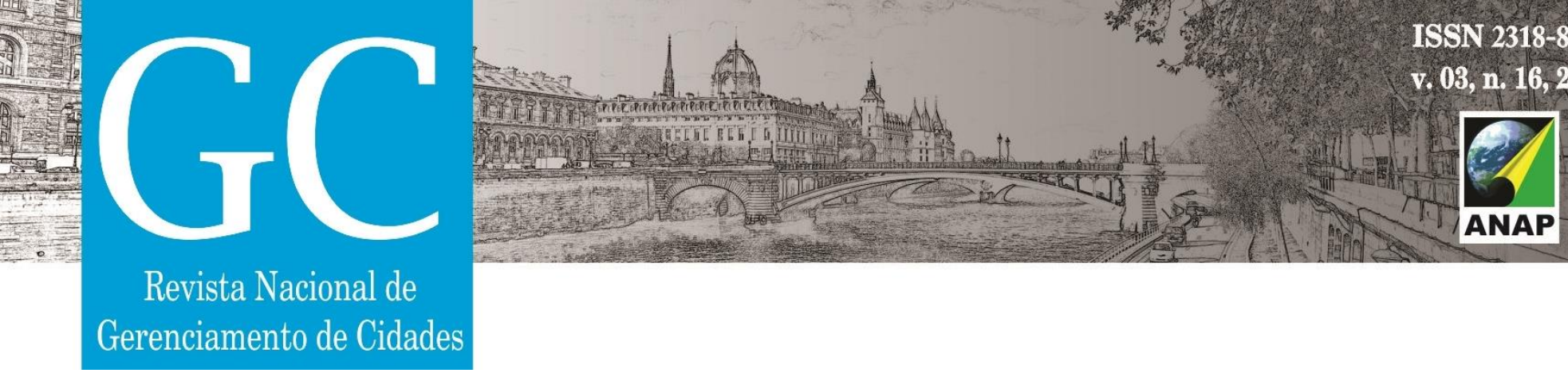

Figura 1 - Vista Bairro Belvedere, Regional Veneza, Distrito Sede. 0

bairro foi aprovado no início da década de 2000 e ainda assim

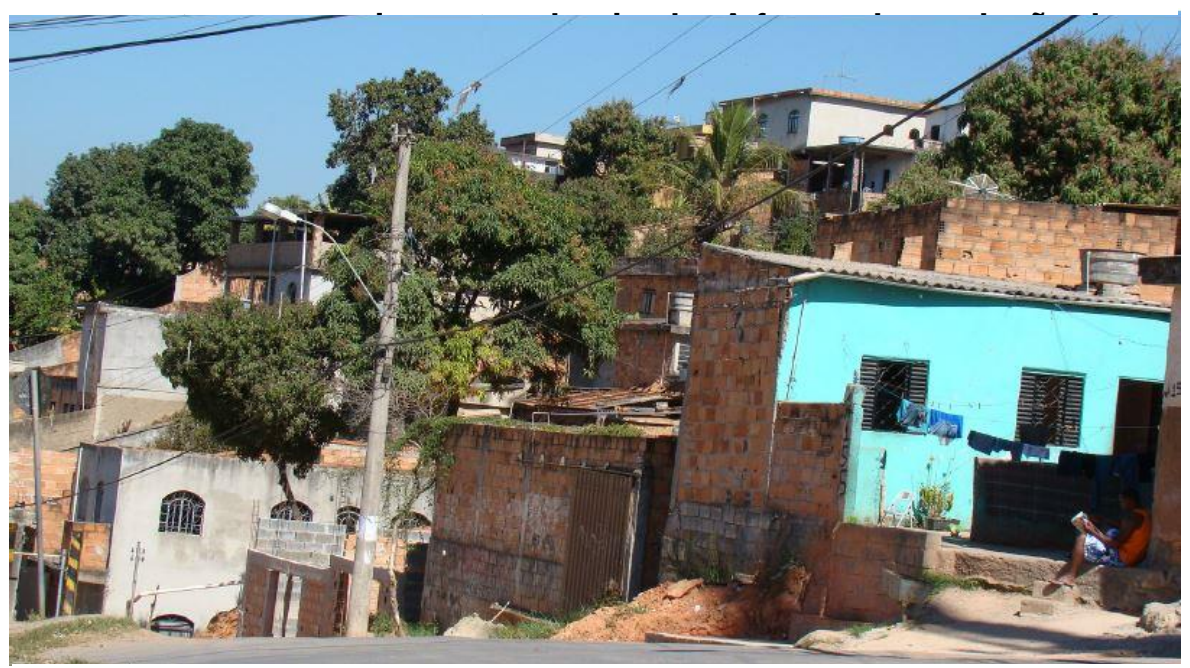

Fonte: Arquivo Pessoal, 2014.

Figura 2 - Vista Bairro Botafogo, Distrito de Justinópolis. Aprovado na

década de 1950, o bairro é precariamente urbanizado e a forma de produção

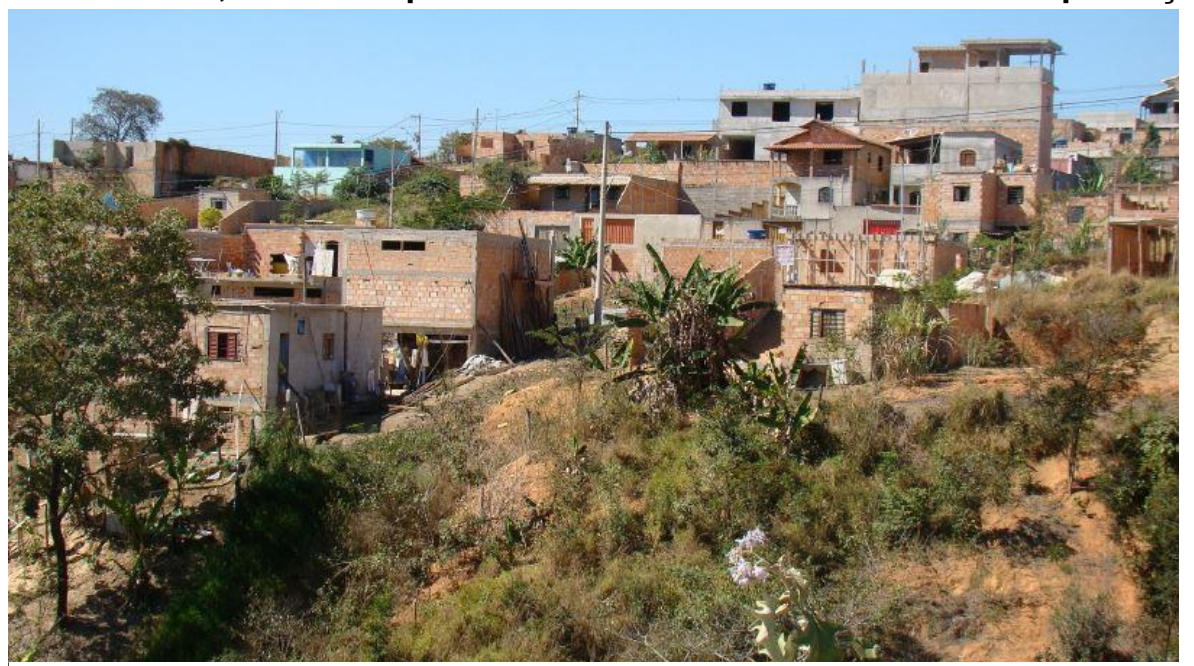

Fonte: Arquivo Pessoal, 2014.

De modo geral o território do município de Ribeirão das Neves encontra-se subordinado pela atuação do governo de Minas Gerais e por capital imobiliário, que estruturam sua ocupação. É tipicamente uma cidade dormitório, muito fragmentada, 


\section{Revista Nacional de}

Gerenciamento de Cidades

ocupada por uma população de baixa renda, caracterizando-se como periferia pobre do Aglomerado Metropolitano ${ }^{5}$.

\section{O PLANO DIRETOR: A CIDADE FORA DO PLANO}

De acordo com o estudo de caso feito pelo Observatório das Metrópoles (2008) o Diagnóstico, realizado com a finalidade de elaboração do Plano Diretor e implementação de suas diretrizes, está em acordo com o que foi observado no município. Entretanto no processo de elaboração do Plano Diretor, em relação à metodologia utilizada, existem contradições no discurso da população civil.

Os procedimentos metodológicos utilizados para a elaboração do Plano Diretor seguiram as seguintes fases de acordo com o diagnóstico do Observatório das Metrópoles (2008):

1) Curso "Plano Diretor de Desenvolvimento Municipal", realizado em novembro de 2002, ministrado por técnicos do Instituto de Desenvolvimento Municipal- IDM, equipe contratada pelo então prefeito de Ribeirão das Neves. Segundo depoimentos de representantes da Prefeitura Municipal e da sociedade civil, esta primeira etapa envolveu a participação de segmentos da Câmara, Sociedade Civil, Líderes Comunitários e representantes da Prefeitura Municipal, dentre outros;

2) "Percursos de Campo", fase que teve como finalidade mapear os principais problemas urbanos do município, realizados em dezembro de 2002 e janeiro de 2003. Fase elaborada por técnicos do IDM e funcionários da prefeitura. A população civil não participou dos "percursos de campo".

3) Reuniões de trabalho, organizadas em Grupos Locais de Trabalho que fizeram sua leitura sobre o processo de desenvolvimento municipal. Essa fase entra em contradição com os relatos da população, uma vez que afirma a participação ativa da sociedade nessa parte do trabalho.

4) Revisão devido à mudança da Administração Municipal, elaborada pela empresa Luiz Mário Queiroz Lima:

\footnotetext{
${ }^{5}$ É denominado Aglomerado Metropolitano, a área compreendida por Belo Horizonte e parte dos municípios vizinhos, que se apresentam como continuidade do tecido urbano deste. (MINAS GERAIS, 2013)
} 


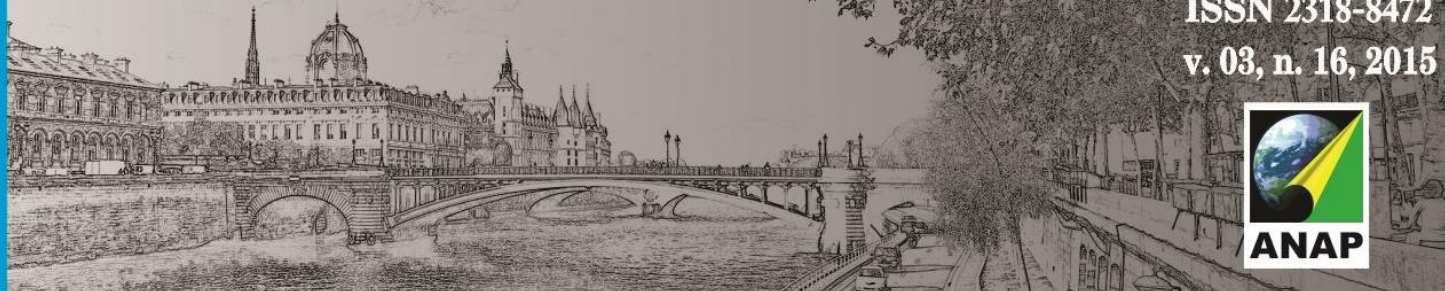

Revista Nacional de

Gerenciamento de Cidades

Nessa nova versão, as anomalias e não conformidades foram identificadas e pelas ferramentas da qualidade total e ambiental, utilizando o método de Pareto e análise de causa-e-efeito, auxiliando a Administração Municipal na tomada de decisão para atender as demandas do município em conformidade com os recursos disponíveis e com as leis de nosso país. (Observatório das Metrópoles, 2008).

Segundo o Observatório das Metrópoles (2008) tal revisão teve que ser feita às pressas para garantir que o prazo previsto pelo Ministério das Cidades fosse cumprido, não houve nova mobilização para a participação popular, ficando a sociedade civil sem participar de reuniões e debates importantes para a finalização do Plano Diretor.

Não somente na sua elaboração, como também na implantação, o Plano Diretor não dispôs de efetiva participação popular. De acordo com o estudo analisado subtende-se que essa ausência ocorreu devido à falta de preparo da Prefeitura de Ribeirão das Neves e dos órgãos competentes de trabalhar com a população, juntamente com a dificuldade em mobilizar e incentivar a população a participar.

Antes da aprovação do Plano Diretor em outubro de 2006, Ribeirão das Neves contava apenas duas leis complementares para regulação e normatização dos parcelamentos do solo ${ }^{6}$ e da construção de conjuntos habitacionais ${ }^{7}$. Tais regulamentações foram propostas devido a uma condição que o município vive em relação à expansão de Belo Horizonte. Assim como dito na parte anterior, Ribeirão das Neves apresentou grande crescimento urbano devido aos loteamentos irregulares implantados. Esses loteamentos, principalmente no distrito de Justinópolis, região que faz divisa com Venda Nova foram a principal consequência do processo de expansão da metrópole.

Apesar desse cenário de precariedade que caracteriza o espaço urbano de Neves, no final do ano de 2006 foi aprovada a Lei Complementar № 036/2006 referente ao Plano Diretor e a Lei Complementar № 037/2006 referente à Lei de Uso e Ocupação do Solo do Município. Com essas duas ferramentas legislativas os governantes atuaram no sentido de efetivar mudanças no processo de expansão de

\footnotetext{
${ }^{6}$ Lei Complementar № 010/97, que dispõe sobre "Normas e Condições para Parcelamento do Solo Urbano e de Expansão Metropolitana no Município de Ribeirão das Neves e dá outras providências".

${ }^{7}$ Lei Complementar № 012/97, que dispõe sobre "Normas e Regulamentações para Construção de Conjuntos Habitacionais no Município de Ribeirão das Neves".
} 
Revista Nacional de

Gerenciamento de Cidades

Neves, seja através da valorização do potencial socioeconômico ou mesmo da introdução de novas formas de uso e ocupação do solo para a regulação urbana (CAMPOS, 2009).

De modo geral, os principais problemas, considerados no Relatório de Diagnóstico e Diretrizes Básicas do PD (volume II, fevereiro de 2006), que contribuíram para a atual situação do município foram a estrutura fundiária fragmentada, ausência de legislação que regulasse o uso e ocupação do solo, estigma de "cidade-presídio" e carência de políticas de desenvolvimento das potencialidades do município.

O PD de Ribeirão das Neves estabelece também condutas para a propriedade urbana desempenhar seu papel social, respondendo aos objetivos para a ordenação da cidade, a exemplo: a revisão da Lei de Uso e Ocupação do Solo (LUOS). Este objetiva minimizar os problemas causados pela produção de loteamentos populares; a recuperação e preservação dos recursos naturais; a criação de mecanismos capazes de inibir o crescimento populacional; a aplicação e fiscalização da legislação urbanística de ordenamento e controle do parcelamento do solo, desestimulando novos parcelamentos para fins residenciais e estimulando o desenvolvimento industrial, agroindustrial e de transportes; a exigência de obras completas de infraestrutura para os novos parcelamentos, entre elas sistema de redes coletoras e de tratamento de esgoto na fase de licenciamento de instalação e a exigência de licenciamento ambiental para os projetos de parcelamento do solo; a garantia, na aprovação de novos loteamentos, da continuidade e articulação do sistema viário existente, entre outras (Lei Complementar № 036/2006).

A Lei de Uso e Ocupação do Solo (LUOS) dispõe diretrizes que convergem com o PD, ditando parâmetros urbanísticos para a estruturação do espaço de Ribeirão das Neves. Estes buscam controlar o adensamento urbano foram criadas zonas que se classificam de acordo com o uso do solo, especificando tamanho dos lotes e tipo de construção que pode ser criada. 


\section{Revista Nacional de}

O PD e a LUOS vigoram desde 2006, entretanto a realidade ainda é majoritariamente a mesma, parece faltar prioridade em programar políticas públicas além do desinteresse e ausência de ajuda do governo estadual.

Segundo Campos (2009) o PD do município parece ser um rol de proposições difusas e não hierarquizadas. A falta de prioridades e objetividade se associa ainda a pouca ou nenhuma capacidade financeira local para implementar qualquer uma das metas do PD sem a ajuda do Estado, que, aparentemente, tem o município apenas como seu "espaço-carcerário".

\section{CONSIDERAÇÕES FINAIS}

Ribeirão das Neves vivenciou um crescimento intenso em um curto intervalo de tempo, resposta a um quadro nacional de segregação das metrópoles brasileiras na época dos anos 1970. Tal momento, em que a fragilidade das políticas de regulação do solo contribuiu para o processo de periferização do município. Essa situação foi desfavorável ao desenvolvimento de um espaço articulado e que concomitantemente com a presença das penitenciárias contribuíram para o cenário precário e segregado que atualmente observa-se na cidade.

O território de Ribeirão das Neves sofre com problemas que foram ocasionados desde o desenvolvimento do seu núcleo urbano: estrutura fundiária fragmentada e desarticulada, presença dos presídios que desvalorizavam os imóveis e os investimentos necessários para o desenvolvimento econômico, não absorção da mão-de-obra local desqualificada, fator este que contribuía para a dependência com Belo Horizonte.

A aprovação do Plano Diretor não contemplou os grandes problemas que o território de Ribeirão das Neves hoje presencia. Além de não possuir em seu texto artigos autoaplicáveis e prazos para elaboração das diretrizes.

Em Ribeirão das Neves os processos decisórios são comandados e coordenados pelo Estado, "de cima para baixo" e "de fora para dentro", ou seja, 


\section{Revista Nacional de}

como instância de poder superior e separada da política local. Esse fato pode ser constatado pelas políticas estatais que tratam a infraestrutura e equipamentos urbanos coletivos a exemplo dos setores privados, sem um real compromisso com os usuários e atendimento a uma necessidade diária, promovendo um contínuo processo de "espoliação urbana".

\section{REFERÊNCIAS BIBLIOGRÁFICAS}

ANDRADE, T. B. Plano Diretor do Município de Ribeirão das Neves. 2009.

ASSOCIAÇÃO BRASILEIRA DE NORMAS TÉCNICAS. NB 1350 - Normas para elaboração de plano diretor. Rio de Janeiro, 1991.

CAMPOS, P. R. O Município de Ribeirão das Neves: um bairro popular em um centro metropolitano. Ano de Obtenção: 2009. 188p. Dissertação (Mestrado em Arquitetura e Urbanismo) Escola de Arquitetura da Universidade Federal de Minas Gerais, UFMG, Minas Gerais.

KOWARICK, L. Autoconstrução de moradias e a espoliação urbana. In: Espoliação urbana. Rio de Janeiro: Paz e Terra, 1979. p. 55-74.

OBSERVATÓRIO DAS METRÓPOLES. Rede de avaliação e capacitação para a implementação dos Planos Diretores Participativos. Estudo de Caso Ribeirão das Neves - Minas Gerais, 2008. Disponível em:

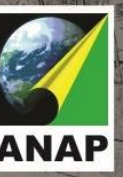

http://www.observatoriodasmetropoles.net/planosdiretores/produtos/mg/Estudo_Caso_PD_Ribeirao_d as_Neves_Rede_PDP_MG.pdf>

PLAMBEL. Plano de Desenvolvimento Integrado de Ribeirão das Neves. Belo Horizonte: [s.n.], 1983.

Plano Diretor de Ribeirão das Neves. Diagnóstico e Diretrizes Básicas. Volume II - Fevereiro 2006 Prefeitura Municipal de Ribeirão Das Neves

RIBEIRÃO DAS NEVES. Prefeitura Municipal. Plano diretor do município de Ribeirão das Neves. Ribeirão das Neves: 2006.2 Disponível em: $<$ http://www.neves.mg.gov.br/ribeiraodasneves/templates/interna_noticia?id_sessao=7\&id_noticia=28 $2>$ acesso 04/março de 2015.

RIBEIRÃO DAS NEVES. Prefeitura Municipal. Lei de Uso e Ocupação do Solo. Ribeirão das Neves: PMRN, 2006. Disponível em: http://www.rmbh.org.br/sites/default/files/MZRM.NEVES.LEl.37.2006.luos.pdf> acesso em 04/ março de 2015. 
